\title{
A pre-operative elevated neutrophil: lymphocyte ratio does not predict survival from oesophageal cancer resection
}

\author{
Farhan Rashid ${ }^{1,3^{*}}$, Naseem Waraich ${ }^{1}$, Imran Bhatti ${ }^{1,3}$, Shopan Saha ${ }^{1}$, Raheela N Khan ${ }^{1,2}$, Javed Ahmed', \\ Paul C Leeder', Mike Larvin ${ }^{1,3}$, Syed Y Iftikhar ${ }^{1,3}$
}

\begin{abstract}
Background: Elevated pre-operative neutrophil: lymphocyte ratio (NLR) has been identified as a predictor of survival in patients with hepatocellular and colorectal cancer. The aim of this study was to examine the prognostic value of an elevated preoperative NLR following resection for oesophageal cancer.

Methods: Patients who underwent resection for oesophageal carcinoma from June 1997 to September 2007 were identified from a local cancer database. Data on demographics, conventional prognostic markers, laboratory analyses including blood count results, and histopathology were collected and analysed.

Results: A total of 294 patients were identified with a median age at diagnosis of 65.2 (IQR 59-72) years. The median pre-operative time of blood sample collection was three days (IQR 1-8). The median neutrophil count was $64.2 \times 10^{-9}$ /litre, median lymphocyte count $23.9 \times 10^{-9}$ /litre, whilst the NLR was 2.69 (IQR 1.95-4.02). NLR did not prove to be a significant predictor of number of involved lymph nodes (Cox regression, $p=0.754$ ), disease recurrence $(p=0.288)$ or death (Cox regression, $p=0.374)$. Furthermore, survival time was not significantly different between patients with high $(\geq 3.5)$ or low $(<3.5)$ NLR $(p=0.49)$.
\end{abstract}

Conclusion: Preoperative NLR does not appear to offer useful predictive ability for outcome, disease-free and overall survival following oesophageal cancer resection.

\section{Introduction}

Human oesophageal carcinoma is considered one of the most aggressive malignancies and is associated with a poor prognosis [1]. Despite recent advancement in surgical and oncological treatment the five year survival remains very poor [2-4]. Oesophagectomy for oesophageal cancer is a major operative intervention which carries a high risk of complications. Hence any means of predicting patients with an inherently poor prognosis or high risk from surgery would be valuable in making treatment recommendations.

Generally agreed prognostic factors for most gastrointestinal cancers include tumour size, marginal resection line involvement, lymph node metastases and tumour differentiation [5]. During the last fifteen years there has been debate about the interaction between

\footnotetext{
* Correspondence: farhan.rashid@nottingham.ac.uk

${ }^{1}$ Royal Derby Hospital, Uttoxeter Road, Derby, DE22 3NE, UK
}

cancer and host inflammatory responses, in particular whether cancer may alter regulation leading to further DNA damage, promotion of angiogenesis, inhibition of apoptosis and increased metastastic susceptibility [6-10]. It is clear that the response of the immune system plays a vital role in the control and progression of many disease states including cancer. Simple measures of immune responsiveness include simple routine biochemical and haematological markers such as total and differential leukocyte counts and C-reactive protein (CRP), which have been proposed as diagnostic and prognostic factors for a variety of cancers $[11,12]$. This may permit a simple estimate of inflammatory response to cancer which is easily assessed in everyday clinical practice.

CRP is the most commonly used measure of systemic inflammation in clinical practice, and has been shown to be an independent predictor of survival in patients 
undergoing resectional surgery for colorectal cancer $[13,14]$. Haematological factors which have been scrutinised for prognostic value include lymphocyte count, neutrophil count and neutrophil: lymphocyte ratio in patients undergoing surgery for pancreatic ductal cancer, epithelial ovarian cancer and hepatic resection of colorectal liver metastases $[15,11,16]$. The effect does not appear to be restricted to major surgical interventions as an elevated NLR has also been shown to predict a poor outcome from interventional procedures for vascular and cardiovascular diseases $[17,18]$.

All patients undergoing oesophagectomy have preoperative full blood counts taken routinely. The NLR can be calculated easily from the data already available. NLR and other inflammatory markers have been identified as a predictor of outcome in patients undergoing potentially curative resection for other gastrointestinal cancers, including hepatocellular and colorectal carcinoma $[13,15,16,19]$. The role of NLR in patients undergoing oesophageal cancer resection does not yet appear to have been studied. The present study was carried out to examine the hypothesis that an elevated pre-operative NLR might prove a clinically useful prognostic indicator for post-operative survival and disease free interval following oesophageal cancer resection. Prognosis would be assessed against standard clinical and histopathological data.

\section{Materials and methods}

\section{Study subjects}

A retrospective analysis was carried out in accordance with UK clinical research governance guidelines, and was approved by our institutional audit department. Patients who underwent surgical resection for oesophageal cancer from June 1997 to September 2007 were identified from our local database for oesophageal cancer. Demographic details, pre-operative staging data, operation type, histopathological diagnosis, staging and survival were extracted from the database. Pathological staging was determined using the American Joint Committee on Oesophageal Cancer staging, which stages tumours according to a revised tumour node metastasis (TNM) system. All patients were followed up in outpatient clinics at regular intervals. First follow up was undertaken at 6 weeks following surgery and subsequently after 3 months, 6 months, 9 months, 1 year and thereafter at every six months interval. Survival data was analysed in October 2007.

\section{Calculation of Neutrophil lymphocyte ratio}

Routine full blood count (FBC) results were collected as part of standard diagnostic and pre-operative protocols. The NLR was calculated as a simple ratio between the absolute neutrophil and the absolute lymphocyte counts, as provided from the differential white cell count output
Table 1 Demographics and preoperative haematology results from patients with resected oesophageal cancer.

\begin{tabular}{ll}
\hline Demographics \\
\hline No of patients identified & 294 \\
\hline Male/Female & $235: 59$ \\
\hline Median age (IQR) & $65.2(59-72)$ years \\
\hline
\end{tabular}

$\overline{\text { Overall median survival (IQR) } 22(14-90) \text { months }}$

\begin{tabular}{ll}
\hline Histological subtypes & \\
\hline Adenocarcinoma & $238(81 \%)$ \\
\hline Scquamous cell carcinoma & $50(17 \%)$ \\
\hline
\end{tabular}

\begin{tabular}{ll}
\hline Preoperative FBC available & 294 \\
\hline Median neutrophil count (IQR) & $64.2 \times 10^{-9} /$ litre, (58-71) \\
\hline Median lymphocyte count (IQR) & $23.9 \times 10^{-9} /$ litre, (17-30) \\
\hline Neutrophil lymphocyte ratio(IQR) & $2.69,(1.95-4.02)$. \\
\hline $\begin{array}{l}\text { Median timing of preoperative FBC } \\
\text { (IQR) }\end{array}$ \\
\hline
\end{tabular}

\begin{tabular}{ll}
\hline Neutrophilia $\left(>7.5 \times 10^{6} / \mathrm{ml}\right)$ & $265(94 \%)$ \\
\hline Lymphocytopenia $\left(<1.0 \times 10^{6} / \mathrm{ml}\right)$ & $57(20 \%)$ \\
\hline
\end{tabular}

from a standard Coulter ${ }^{\circ}$ counter (Model, XE2100, Sysmex, Japan).

\section{Statistical methods}

The distribution of continuous variables was tested for normality using the Kolmogorov-Smirnov test and Q-Q plots. All continuous variables were skewed therefore the results were reported as medians Interquartile range (IQR)\}. The Spearman's correlation coefficient was used to assess the association between continuous variables. The Mann-Whitney U test was calculated for comparison of two groups and the Kruskal-Wallis test was used to compare more than two groups. Cox regression and Kaplan-Meier analysis was utilised to assess the predictive value for NLR, neutrophil and lymphocyte counts for hazard of death. The Kaplan-Meier curves were compared using the Log Rank test. The Cox regression models were constructed using the Forward: Likelihood ratio method with $\mathrm{p}$ value less than 0.05 as the entry criterion to the model for the independent variables. The hazard risk (HR) from the Cox Regression analysis was not presented for non significant specific variables that were tested. The Chi-Square test was used to test the association between NLR groups (Cut-offs of 3, 3.5, 4 and 5) and recurrence, 


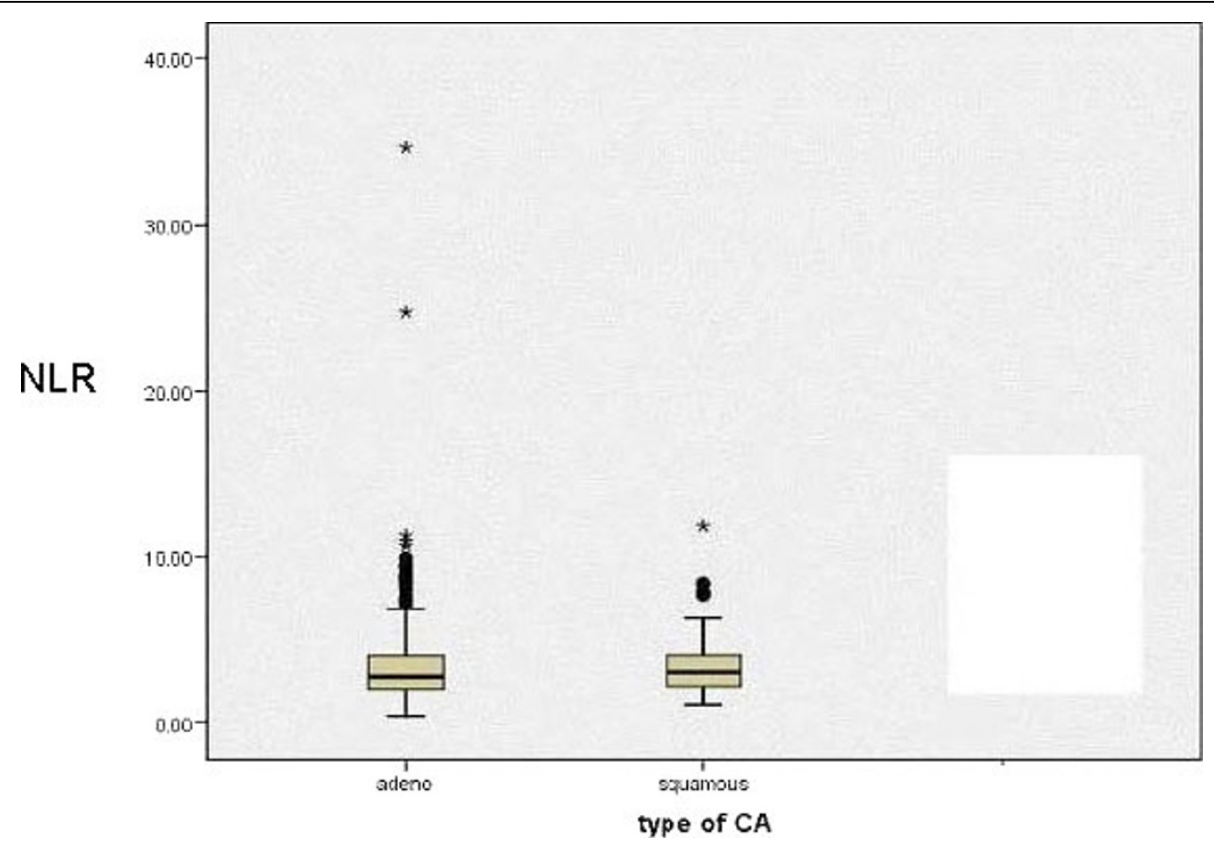

Figure 1 NLR median and IQR box plot for three oesophageal cancer groups.

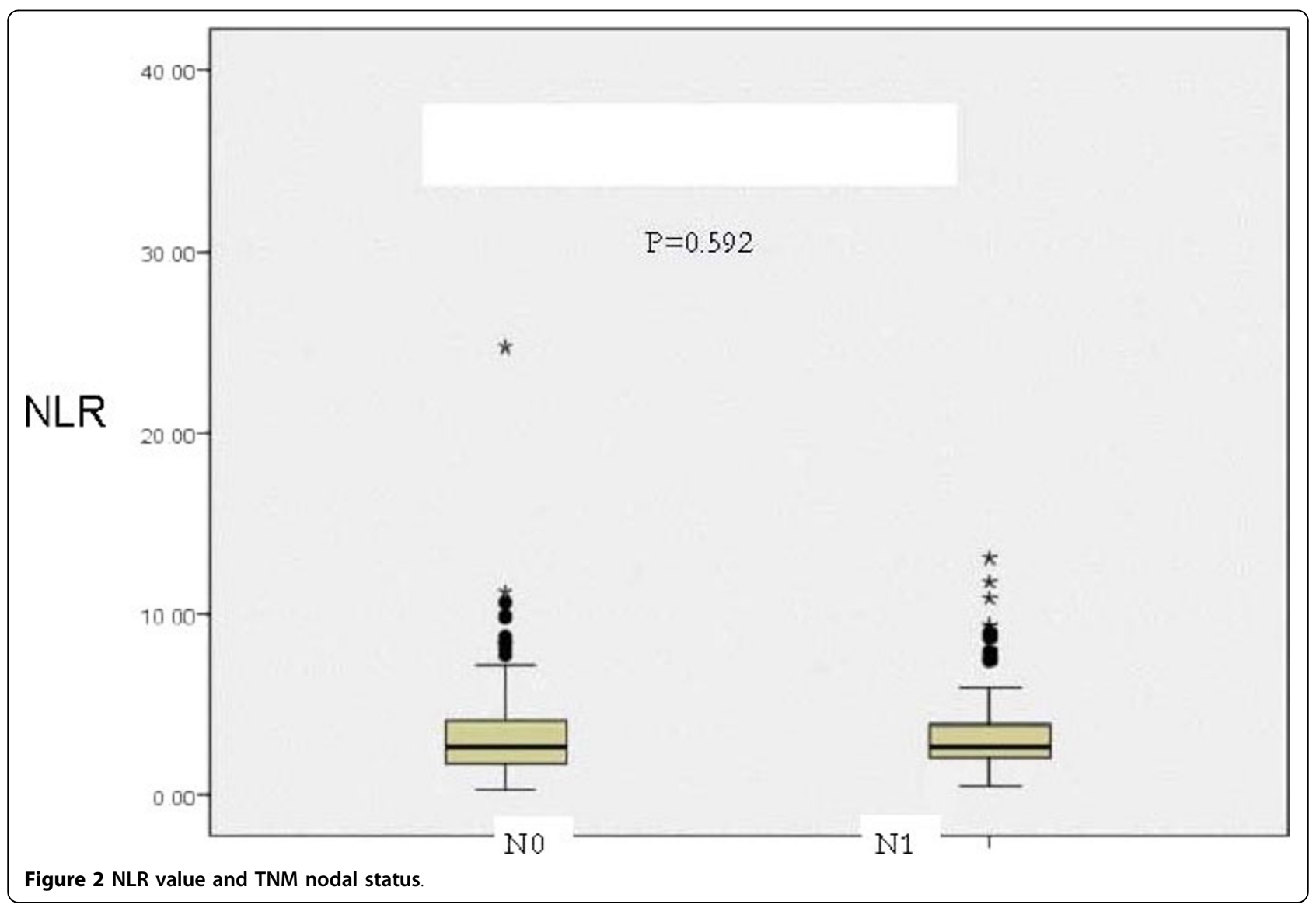




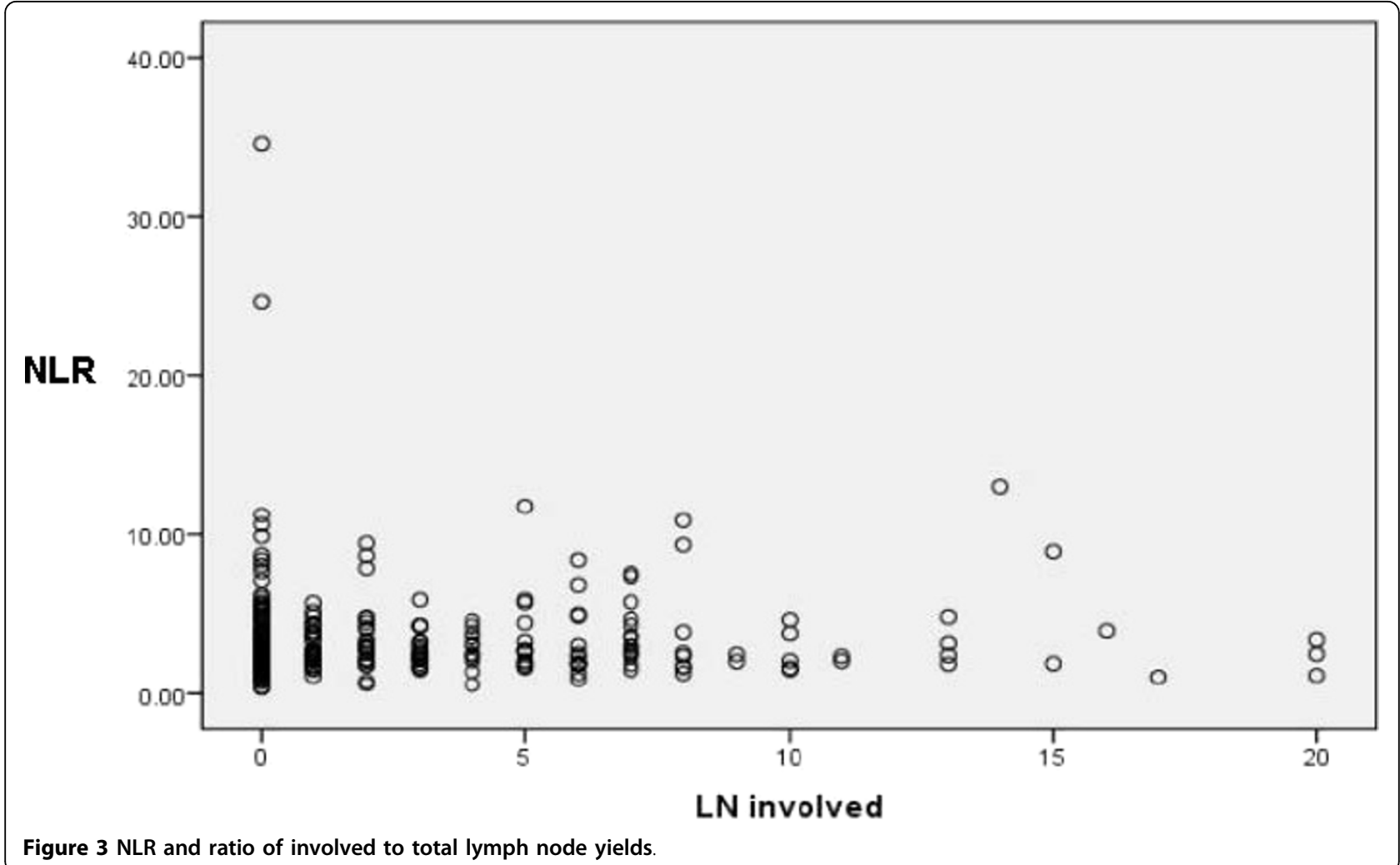

Tumour (T)-stage, Nodal (N) stage and histological subtype of cancer.

SPSS version 16.0 was used for statistical analysis (SPSS, Woking, Surrey UK). An alpha probability ( $p$ value) of less than $5 \%(0.05)$ was considered significant.

\section{Results (Table 1)}

Of 294 patients studied, there were 235 males and 59 females. The median age at diagnosis was 65.2 years (IQR 59-72). There were 238 adenocarcinomas (81\%), 50 squamous cell cancers $(17 \%)$ and 6 other cancers (2\%) comprising 2 gastrointestinal stromal tumours, one oat cell cancer and three undifferentiated oesophageal tumours. The median time for pre-operative FBC sample collection was 3 days, (IQR: 1 - 8). No patient exhibited clinical signs of sepsis in the pre-operative period.

Neutrophil: lymphocyte ratio (Table 1)

The overall median neutrophil count was $64.2 \times 10^{-9} /$ litre, IQR 58.6-71.0, the median lymphocyte count 23.9 $\times 10^{-9}$ /litre, IQR $17.8-30.0$ and the NLR was 2.69, IQR 1.95-4.02).

\section{NLR as a predictor of death}

NLR was not a significant predictor of hazard of death (Cox Regression analysis, $\mathrm{p}=0.374$ ).

\section{NLR and age}

There was no significant correlation between age and NLR ( $r=0.094, p=0.117$, Spearman's correlation coefficient).

Neutrophil: lymphocyte ratio in cancer subsets (Figure 1) (Table 1)

NLR values were not significantly different between patients within the two different types of cancer (adenocarcinoma 2.69, IQR 1.32-3.96 and squamous cell carcinoma 2.98, IQR 2.10-4.10. Mann Whitney $U$ test $\mathrm{p}=$ 0.740) (Figure 1).

\section{NLR and nodal status}

NLR values were not significantly different between TNM subsets of lymph node status. The median NLR in pN0 (no lymph node metastasis) patients was 2.69, IQR 1.75-4.10 and in pN1 (regional lymph node metastasis) patients was 2.69, IQR 2.08-3.93, which was not significantly different $(\mathrm{p}=0.592)$. (Figure 2$)$. NLR value was not significantly correlated with either the lymph node yield, $(\mathrm{r}=0.28, \mathrm{p}=0.644)$ nor with the involved lymph node $(\mathrm{r}=0.42, \mathrm{p}=0.493)$ (Figure 3$)$.

\section{NLR and $\mathrm{T}$ stage}

There was no relationship between different NLR cut off values $(3,3.5,4$ and 5$)$ and the depth of invasion or $\mathrm{T}$ stage ( $p$ values of $0.624,0.937,0.866$ and 0.522 respectively). 


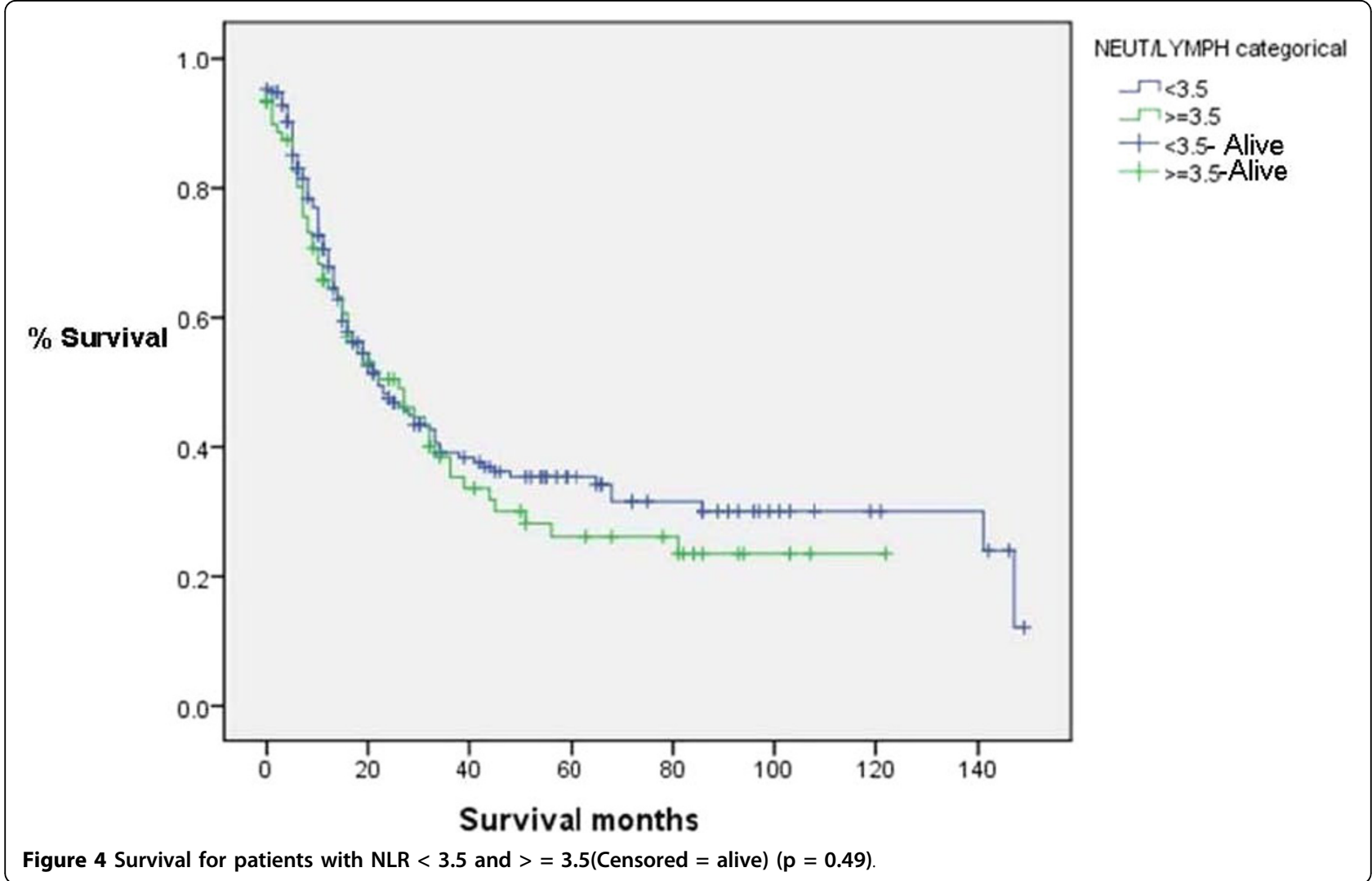

\section{NLR and disease recurrence (Table 2)}

There was no significant relationship between NLR values and the probability of disease recurrence (recurrence free 2.82 IQR1.78-4.07, $\mathrm{P}=0.82$, and recurrent disease 2.79 IQR 2.12-4.28, $\mathrm{P}=0.288)$.

\section{NLR vs Survival (Figure 4, 5, 6 \&7)}

NLR was grouped into different cut-off points (3, 3.5, 4 and 5) to find whether there was any significant difference in survival. There was no significant difference in survival between patients with NLR values of greater than or equal to 3.5 and those with an NLR of less than 3.5. The median overall survival was 22 months, IQR 1490. Survival time was not statistically significantly different between groups with NLR $\geq 3.5$ and those with $<3.5$ $(p=0.49)$. Similarly, the choice of other NLR cutt offs (3, 4 and 5) did not show any significant difference in survival (p values of $0.340,0.680$ and 0.868 respectively).

\section{NLR and preoperative chemotherapy}

Fourty four patients had preoperative chemotherapy as compared to 250 patients who underwent surgery as

Table 2 NLR values and disease recurrence

\begin{tabular}{llll}
\hline & NLR & IQR & P-Value \\
\hline Recurrence Free & 2.82 & $1.78-4.07$ & 0.288 \\
\hline Recurrence & 2.79 & $212-4.28$ & 0.288 \\
\hline
\end{tabular}

first line treatment without neo-adjuvant chemotherapy. The neutrophil count for patients with chemotherapy (Median 57.8, (49-64.7)) was lower than patients without chemotherapy (Median 65.3, (60-72), p < 0.001). However, the patients with chemotherapy had higher lymphocyte count (Median 31, 22-37) as compared to those without preoperative chemotherapy (Median 22.7 (1728.6), p < 0.001). Median NLR of those who had chemotherapy was 1.86 (IQR, 1.3-2.9) and those without chemotherapy was 2.8 (IQR, 2.1-4.3) ( $\mathrm{p}<0.001)$. There was no survival difference in patients with or without chemotherapy $(p=0.323)$. In addition, adjusting for NLR, there was no difference in survival for patients who had received preoperative chemotherapy as compared to those without neoadjuvant chemotherapy ( $\mathrm{p}=$ 0.280 , Cox regression analysis with interaction term).

NLR cut off values and type of cancer (Table 3 )

Different values of NLR have been used as a predictor of prognosis [15]. A cut off value 3.5 has also not shown any significant association between two sub-types of oesophageal cancer and NLR values.

\section{Discussion}

Leukocytes were first discovered in malignant tissue specimens by the pathologist Rudolf Virchow about 150 years ago [6]. Inflammation not only plays a vital role in 


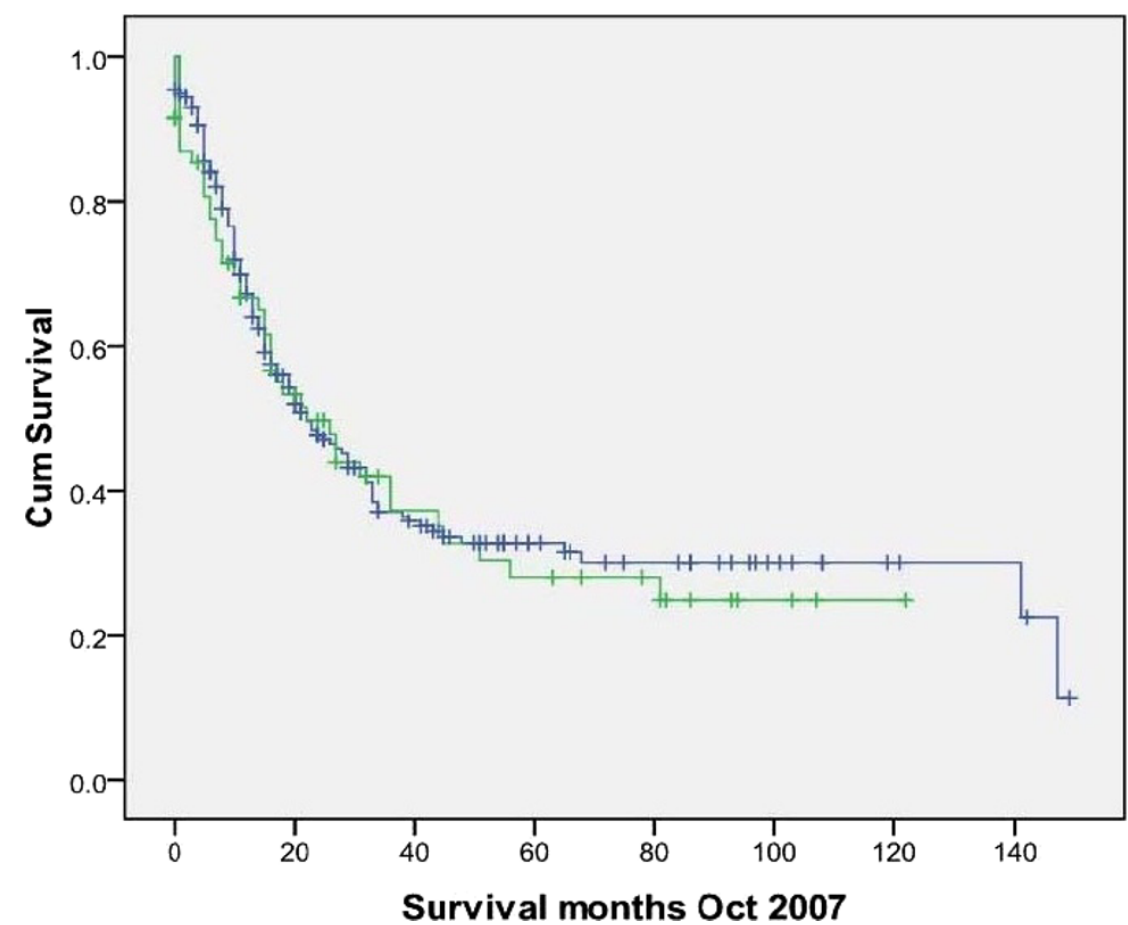

NEUT/LYMPH

categorical (4)

$-\neg<4$

$\neg>=4$

$+<4$-Alive

$+>=4$-Alive

Survival months Oct 2007

Figure 5 Survival for patients with NLR $<4$ and $>=4$ (Censored $=$ alive) $(p=0.680)$

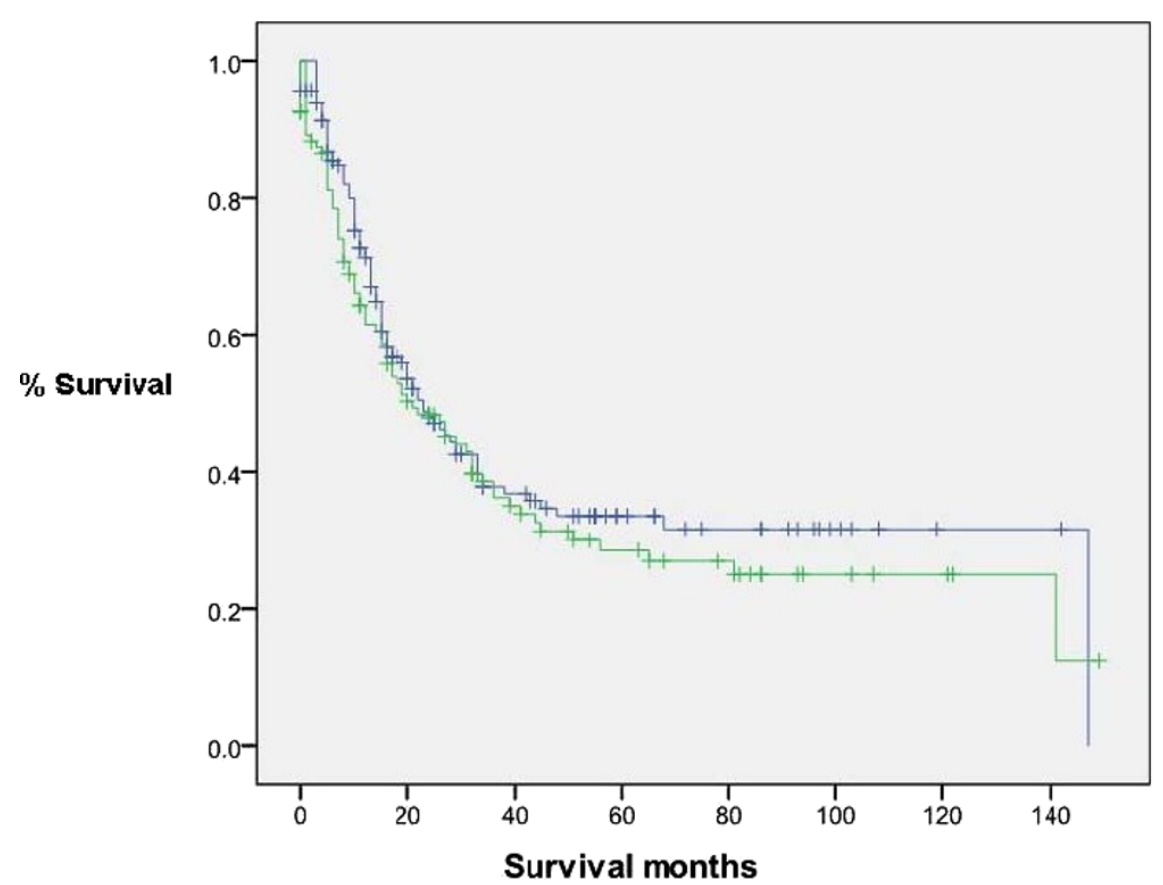

NEUT/LYMPH

categorical (3)

$-\neg<3$

$\neg>=3$

$+<3$-Alive

$+>=3$-Alive

Figure 6 Survival for patients with NLR $<3$ and $>=3$ (Censored $=$ alive) $(p=0.340)$ 


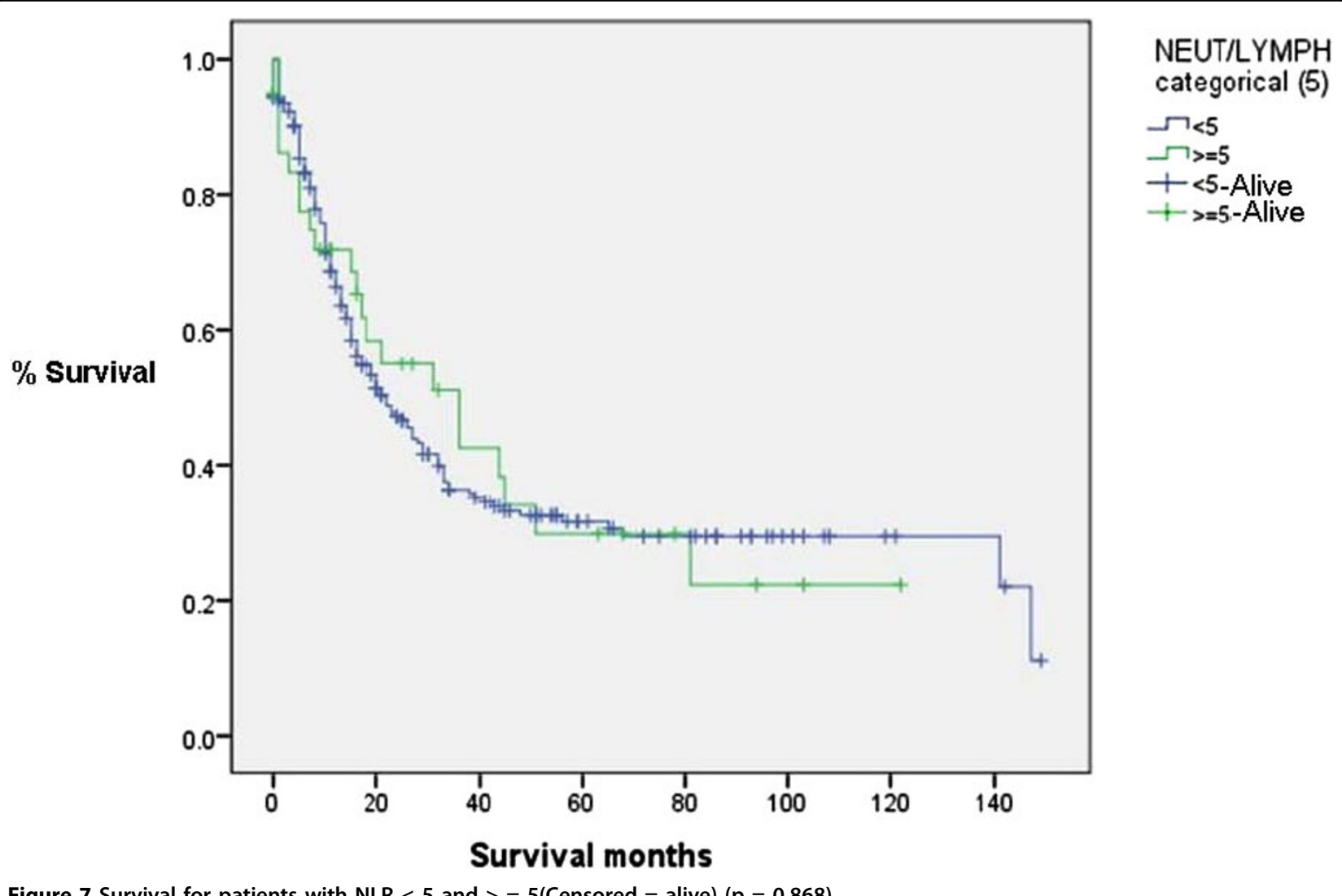

Figure 7 Survival for patients with NLR $<5$ and $>=5$ (Censored = alive) $(p=0.868)$

development but also remains very important in progression of various malignant disease processes including gastrointestinal tract [20-22] and liver cancers [23]. Neutrophilia has been associated with malignancy, although the cause is not completely understood. However, it is a multifactorial process. Research has confirmed a link between the inflammatory microenvironment of a tumour, and systemic responses induced by the tumour. The presence of T-cells in a tumour provides an indication of significant local immune responses [24,25]. For many types of cancer, lymphocytopaenia indicates a generalized state of immunodepression [26], and survival appears to be adversely influenced by depressed immune function. There may be a marked decrease in CD-4 helper lymphocytes and an increase in CD-8 suppressor lymphocytes, signifying depression of innate cellular immunity [27]. Depression in T-cell function may attenuate the tumour specific response. Major surgery in cancer patients is known to reduce lymphocyte metabolism, as measured by adenosine triphosphate production, which leads to functional impairment [28]. In addition, the microenvironment within the tumour can also influence on the invading leukocytes to enhance angiogenesis, invasion, motility and viability $[6,7,29,30]$.
The malignant process also produces myeloid growth factors as part of a paraneoplastic syndrome and this may be one of the causes of neutrophilia. In addition, another factor granulocyte colony stimulating factor produced by the malignant cells has also been attributed to be the cause of neutrophilia because of its action on bone marrow granulocytic cells [31-35]. Apart from the production of myeloid growth factors, cancer inflammation and associated neutrophilia have also been associated with the release of IL- 6 (interleukin-6) and TNF$\alpha$ (Tumour necrosis factor- $\alpha$ ) [36-39].

Some variations have been observed in different cancers. Patients with pancreatic ductal adenocarcinoma have been identified as having more marked lymphocytopenia preoperatively and postoperatively, when compared with patients having gastric and colorectal carcinoma [39]. Previous studies have suggested different NLR values as a prognostic marker $[15,17,40]$. The preoperative NLR of greater than 5 was elevated in only around $15 \%$ of our patients as compared to $32 \%$ in the study published by Walsh et al in patients with colorectal cancer. In addition, majority of the patients (94\%) in our study had neutrophilia as compared to near normal neutrophil count in most of the patients undergoing resection of pancreatic ductal adenocarcinoma [16]. 

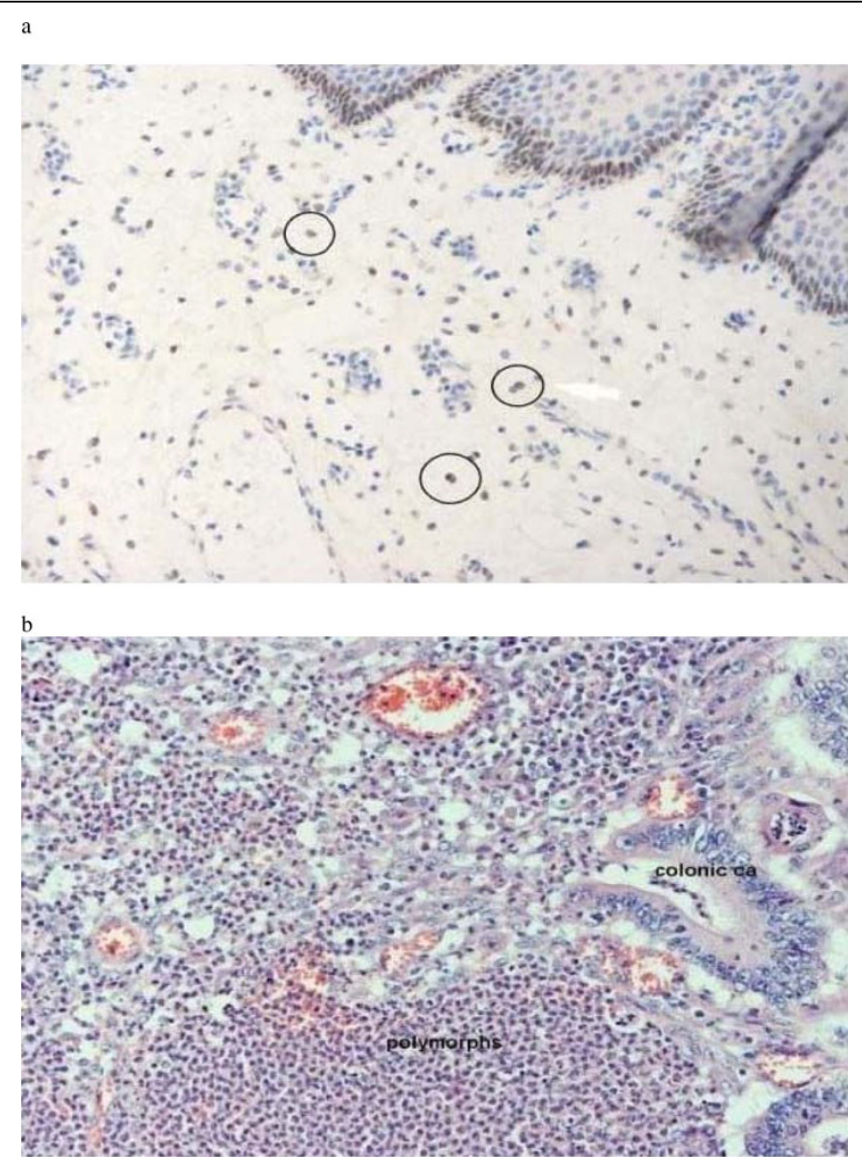

Figure 8 a Oesophageal cancer histopathology: there is marked dysplastic change but little polymorphic infiltration. 8b: Colonic tumour with excessive polymorphic infiltration but little dysplasia.

Table 3 Association between the type of cancer and NLR $>=3.5$ and $<3.5$

\begin{tabular}{lllll}
\hline $\begin{array}{l}\mathbf{p = 0 . 9 8 4} \\
\text { (Chi Square test) }\end{array}$ & $\begin{array}{l}\text { NLR } \\
<\mathbf{3 . 5}\end{array}$ & $\boldsymbol{> = 3 . 5}$ & Total \\
\hline Adeno & $\mathrm{n}$ & 165 & 71 & 236 \\
\hline \multirow{3}{*}{ Squamous } & $\%$ & $81.3 \%$ & $80.7 \%$ & $81.1 \%$ \\
& $\mathrm{~N}$ & 34 & 15 & 49 \\
& $\%$ & $16.7 \%$ & $17.0 \%$ & $16.8 \%$ \\
\hline
\end{tabular}

The oesophageal tumour occurs more frequently in males and such tumours have a worst prognosis when compared to their female counterparts [1]. The gender effects on the changes of circulating subtypes of white cells, the differences in endocrine reactions to the nature of the stress have been studied and certain variations in immune response between males and females have also been reported [41-44]. The females have shown a more immunocompromised response as compared the male patients [41]. Although the immune response is multifactorial, the male predominance of oesophageal cancer (male to female ratio of 4:1 in this study) may be one of the reasons why NLR does not work as a predictor in our study as compared to the other studies.

All these factors may explain the variance in the results of our study compared to others undertaken in different cancers.

Inflammation is known to play a role in some colorectal cancers. This includes causation, with ulcerative colitis known to involve recurrent ulceration, epithelial regeneration dysplasia and in some cases malignant change. Oesophageal cancer can be preceded by Barrett's oesophagus, also a chronic inflammatory process involving metaplasia (figure $8 \mathrm{a} \& 8 \mathrm{~b}$ ). However the majority of gastrointestinal tract cancers do not arise as a result of overt acute or chronic inflammation. Nevertheless, cancer invokes a host inflammatory reaction as a consequence.

Immunosurveillance for cancer fails as humans age $[45,46]$, and this may also explain changes in neutrophil and lymphocyte counts in oesophageal cancer, predominantly a disease of older patients. $58 \%$ of our patients were over 60 years of age, in keeping with most published series. 
Our cohort includes only those oesophageal cancer patients who had resectable disease and underwent surgery and does not include those who underwent palliative treatment. This exclusion of the patients with metastatic disease remains a shortcoming of the study.

In conclusion, the present study failed to confirm that NLR was a significant predictor of survival, recurrence and nodal involvement following resection for oesophageal cancer.

\section{Conflict of interests}

The authors declare that they have no competing interests.

\section{Abbreviations}

CRP: C-reactive protein; CA: carcinoma; DNA: deoxyribonucleic acid; FBC: full blood count; IQR: interquartile range; LN: lymph node; NLR: neutrophil lymphocyte ratio.

\section{Acknowledgements}

We are grateful to Mr Apostolos Fakis (Statistician), Dr D Sameraro and Mrs Andrea Gooding (Pathology Department) Royal Derby Hospital, Derby, UK for their help in the study. We are also thankful to Dr Jay Kwon (F1, Royal Derby Hospital, and Derby, UK) for his help in data collection.

\section{Author details}

${ }^{1}$ Royal Derby Hospital, Uttoxeter Road, Derby, DE22 3NE, UK. ${ }^{2}$ School of Graduate Entry Medicine and Health, Derby, University of Nottingham, Uttoxeter Road, Derby, DE22 3DT, UK. ${ }^{3}$ Academic Division of Upper Gl Surgery, School of Graduate Entry Medicine and Health, University of Nottingham, The Medical School Derby, DE22 3DT, UK.

\section{Authors' contributions}

FR has designed, carried out the study. FR and NW helped in data collection. FR, NW and IB have performed the analysis. JA, PCL, MLA and SYI provided the supervision. FR wrote the manuscript. $P C L, R N K, M L A$ and SYI edited the manuscript. All authors contributed to the manuscript, and all read and approved the final version.

\section{Received: 19 August 2009}

Accepted: 6 January 2010 Published: 6 January 2010

\section{References}

1. Tanaka S, Ueo H, Mafune K, Mori M, Wands JR, Sugimachi K: A novel isoform of human fibroblast growth factor 8 is induced by androgens and associated with progression of esophageal carcinoma. Dig Dis Sci 2001, 46(5):1016-1021.

2. Tanaka S, Hirabayashi Y: International Comparisons of Cumulative Risk of Oesophagus Cancer, from Cancer Incidence in Five Continents Vol. VIII. Jpn J Clin Oncol 2006, 36(9):609-610.

3. Pye JK, Crumplin MK, Charles J, Kerwat R, Foster ME, Biffin A: One-year survey of carcinoma of the oesophagus and stomach in Wales. $\mathrm{Br} J$ Surg 2001, 88(2):278-285.

4. Thomas P, Doddoli C, Lienne P, Morati N, Thirion X, Garbe L, Giudicelli R, Fuentes $P$ : Changing patterns and surgical results in adenocarcinoma of the oesophagus. Br J Surg 1997, 84(1):119-125.

5. Omloo JM, Sloof GW, Boellaard R, Hoekstra OS, Jager PL, van Dullemen HM, Fockens P, Plukker JT, van Lanschot JJ: Importance of fluorodeoxyglucosepositron emission tomography (FDG-PET) and endoscopic ultrasonography parameters in predicting survival following surgery for esophageal cancer. Endoscopy 2008, 40(6):464-471.

6. Balkwill F, Mantovani A: Inflammation and cancer: back to Virchow?. Lancet 2001, 357(9255):539-545.

7. Coussens LM, Werb Z: Inflammation and cancer. Nature 2002, 420(6917):860-867.
8. Gunter MJ, Stolzenberg-Solomon R, Cross AJ, Leitzmann MF, Weinstein S, Wood RJ, Virtamo J, Taylor PR, Albanes D, Sinha R: A prospective study of serum C-reactive protein and colorectal cancer risk in men. Cancer Res 2006, 66(4):2483-2487.

9. Jackson JR, Seed MP, Kircher CH, Willoughby DA, Winkler JD: The codependence of angiogenesis and chronic inflammation. FASEB J 1997, 11(6):457-465.

10. Jaiswal M, LaRusso NF, Burgart LJ, Gores GJ: Inflammatory cytokines induce DNA damage and inhibit DNA repair in cholangiocarcinoma cells by a nitric oxide-dependent mechanism. Cancer Res 2000, 60(1):184-190.

11. Cho H, Hur HW, Kim SW, Kim SH, Kim JH, Kim YT, Lee K: Pre-treatment neutrophil to lymphocyte ratio is elevated in epithelial ovarian cancer and predicts survival after treatment. Cancer Immunol Immunother 2008, 58(1):15-23.

12. Ueno $H$, Hawrylowicz $C M$, Banchereau J: Immunological intervention in human diseases. J Transl Med 2007, 5:59.

13. McMillan DC, Canna K, McArdle CS: Systemic inflammatory response predicts survival following curative resection of colorectal cancer. $\mathrm{Br} \mathrm{J}$ Surg 2003, 90(2):215-219.

14. McMillan DC, Wotherspoon HA, Fearon KC, Sturgeon C, Cooke TG, McArdle CS: A prospective study of tumor recurrence and the acutephase response after apparently curative colorectal cancer surgery. Am J Surg 1995, 170(4):319-322.

15. Halazun KJ, Aldoori A, Malik HZ, Al-Mukhtar A, Prasad KR, Toogood GJ, Lodge JP: Elevated preoperative neutrophil to lymphocyte ratio predicts survival following hepatic resection for colorectal liver metastases. Eur J Surg Oncol 2008, 34(1):55-60.

16. Clark EJ, Connor S, Taylor MA, Madhavan KK, Garden OJ, Parks RW: Preoperative lymphocyte count as a prognostic factor in resected pancreatic ductal adenocarcinoma. HPB (Oxford) 2007, 9(6):456-460.

17. Duffy BK, Gurm HS, Rajagopal V, Gupta R, Ellis SG, Bhatt DL: Usefulness of an elevated neutrophil to lymphocyte ratio in predicting long-term mortality after percutaneous coronary intervention. Am J Cardiol 2006, 97(7):993-996.

18. Zahorec R: Ratio of neutrophil to lymphocyte counts-rapid and simple parameter of systemic inflammation and stress in critically ill. Bratis/ Lek Listy 2001, 102(1):5-14.

19. Walsh SR, Cook EJ, Goulder F, Justin TA, Keeling NJ: Neutrophil-lymphocyte ratio as a prognostic factor in colorectal cancer. J Surg Oncol 2005, 91(3):181-184.

20. Biarc J, Nguyen IS, Pini A, Gosse F, Richert S, Thierse D, Van Dorsselaer A, Leize-Wagner E, Raul F, Klein JP, Scholler-Guinard M: Carcinogenic properties of proteins with pro-inflammatory activity from Streptococcus infantarius (formerly S. bovis). Carcinogenesis 2004, 25(8):1477-1484.

21. Brower $V$ : Feeding the flame: new research adds to role of inflammation in cancer development. J Natl Cancer Inst 2005, 97(4):251-253.

22. Jaiswal M, LaRusso NF, Gores GJ: Nitric oxide in gastrointestinal epithelial cell carcinogenesis: linking inflammation to oncogenesis. Am J Physiol Gastrointest Liver Physiol 2001, 281(3):G626-634.

23. Bartsch $H$, Nair J: Oxidative stress and lipid peroxidation-derived DNAlesions in inflammation driven carcinogenesis. Cancer Detect Prev 2004, 28(6):385-391.

24. Ropponen KM, Eskelinen MJ, Lipponen PK, Alhava E, Kosma VM: Prognostic value of tumour-infiltrating lymphocytes (TILs) in colorectal cancer. $J$ Pathol 1997, 182(3):318-324.

25. Dolcetti R, Viel A, Doglioni C, Russo A, Guidoboni M, Capozzi E, Vecchiato N, Macri $E$, Fornasarig $M$, Boiocchi M: High prevalence of activated intraepithelial cytotoxic T lymphocytes and increased neoplastic cell apoptosis in colorectal carcinomas with microsatellite instability. Am J Pathol 1999, 154(6):1805-1813.

26. Wenger FA, Jacobi CA, Zieren J, Docke W, Volk HD, Muller JM: Tumor size and lymph-node status in pancreatic carcinoma - is there a correlation to the preoperative immune function?. Langenbecks Arch Surg 1999, 384(5):473-478.

27. Menges T, Engel J, Welters I, Wagner RM, Little S, Ruwoldt R, Wollbrueck M, Hempelmann G: Changes in blood lymphocyte populations after multiple trauma: association with posttraumatic complications. Crit Care Med 1999, 27(4):733-740.

28. Mukherjee M, Sahasrabuddhe MB: Effect of operation on peripheral lymphocyte counts and production of adenosine triphosphate (ATP) in cancer patients. J Surg Oncol 1982, 20(1):1-8. 
29. Hanahan D, Weinberg RA: The hallmarks of cancer. Cell 2000, 100(1):57-70.

30. Lin EY, Pollard JW: Role of infiltrated leucocytes in tumour growth and spread. Br J Cancer 2004, 90(11):2053-2058.

31. Lord BI, Bronchud MH, Owens S, Chang J, Howell A, Souza L, Dexter TM: The kinetics of human granulopoiesis following treatment with granulocyte colony-stimulating factor in vivo. Proc Natl Acad Sci USA 1989, 86(23):9499-9503.

32. Ulich TR, del Castillo J, Watson LR, Yin SM, Garnick MB: In vivo hematologic effects of recombinant human macrophage colony-stimulating factor. Blood 1990, 75(4):846-850.

33. Aglietta M, Piacibello W, Sanavio F, Stacchini A, Apra F, Schena M, Mossetti C, Carnino F, Caligaris-Cappio F, Gavosto F: Kinetics of human hemopoietic cells after in vivo administration of granulocytemacrophage colony-stimulating factor. J Clin Invest 1989, 83(2):551-557.

34. Price TH, Chatta GS, Dale DC: Effect of recombinant granulocyte colonystimulating factor on neutrophil kinetics in normal young and elderly humans. Blood 1996, 88(1):335-340.

35. Uchida T, Yamagiwa A: Kinetics of rG-CSF-induced neutrophilia in mice. Exp Hematol 1992, 20(2):152-155.

36. Ulich TR, del Castillo J, Guo K, Souza L: The hematologic effects of chronic administration of the monokines tumor necrosis factor, interleukin-1, and granulocyte-colony stimulating factor on bone marrow and circulation. Am J Pathol 1989, 134(1):149-159.

37. Ulich TR, del Castillo J, Guo KZ: In vivo hematologic effects of recombinant interleukin- 6 on hematopoiesis and circulating numbers of RBCs and WBCs. Blood 1989, 73(1):108-110.

38. Ulich TR, del Castillo J, Keys M, Granger GA, Ni RX: Kinetics and mechanisms of recombinant human interleukin 1 and tumor necrosis factor-alpha-induced changes in circulating numbers of neutrophils and lymphocytes. J Immunol 1987, 139(10):3406-3415.

39. Romano F, Uggeri F, Crippa S, Di Stefano G, Scotti M, Scaini A, Caprotti R: Immunodeficiency in different histotypes of radically operable gastrointestinal cancers. J Exp Clin Cancer Res 2004, 23(2):195-200.

40. Cho H, Hur HW, Kim SW, Kim SH, Kim JH, Kim YT, Lee K: Pre-treatment neutrophil to lymphocyte ratio is elevated in epithelial ovarian cancer and predicts survival after treatment. Cancer Immunol Immunother 2009, 58(1):15-23.

41. Gwak MS, Choi SJ, Kim JA, Ko JS, Kim TH, Lee SM, Park JA, Kim MH: Effects of gender on white blood cell populations and neutrophil-lymphocyte ratio following gastrectomy in patients with stomach cancer. J Korean Med Sci 2007, 22(Suppl):S104-108.

42. Traustadottir T, Bosch PR, Matt KS: Gender differences in cardiovascular and hypothalamic-pituitary-adrenal axis responses to psychological stress in healthy older adult men and women. Stress 2003, 6(2):133-140.

43. Deuster PA, Petrides JS, Singh A, Lucci EB, Chrousos GP, Gold PW: High intensity exercise promotes escape of adrenocorticotropin and cortisol from suppression by dexamethasone: sexually dimorphic responses. $J$ Clin Endocrinol Metab 1998, 83(9):3332-3338.

44. Petrie EC, Wilkinson CW, Murray S, Jensen C, Peskind ER, Raskind MA: Effects of Alzheimer's disease and gender on the hypothalamic-pituitaryadrenal axis response to lumbar puncture stress. Psychoneuroendocrinology 1999, 24(4):385-395.

45. Finch $C E$, Crimmins $E M$ : Inflammatory exposure and historical changes in human life-spans. Science 2004, 305(5691):1736-1739.

46. Krabbe $\mathrm{KS}$, Pedersen $\mathrm{M}$, Bruunsgaard $\mathrm{H}$ : Inflammatory mediators in the elderly. Exp Gerontol 2004, 39(5):687-699.

doi:10.1186/1477-7819-8-1

Cite this article as: Rashid et al: A pre-operative elevated neutrophil: lymphocyte ratio does not predict survival from oesophageal cancer resection. World Journal of Surgical Oncology 2010 8:1.

Publish with Bio Med Central and every scientist can read your work free of charge

"BioMed Central will be the most significant development for disseminating the results of biomedical research in our lifetime. "

Sir Paul Nurse, Cancer Research UK

Your research papers will be:

- available free of charge to the entire biomedical community

- peer reviewed and published immediately upon acceptance

- cited in PubMed and archived on PubMed Central

- yours - you keep the copyright 